Document downloaded from:

http://hdl.handle.net/10251/39809

This paper must be cited as:

Payri, R.; Gimeno, J.; Bardi, M.; Plazas, AH. (2013). Study liquid length penetration results obtained with a direct acting piezo electric injector. Applied Energy. 106:152-162. doi:10.1016/j.apenergy.2013.01.027.

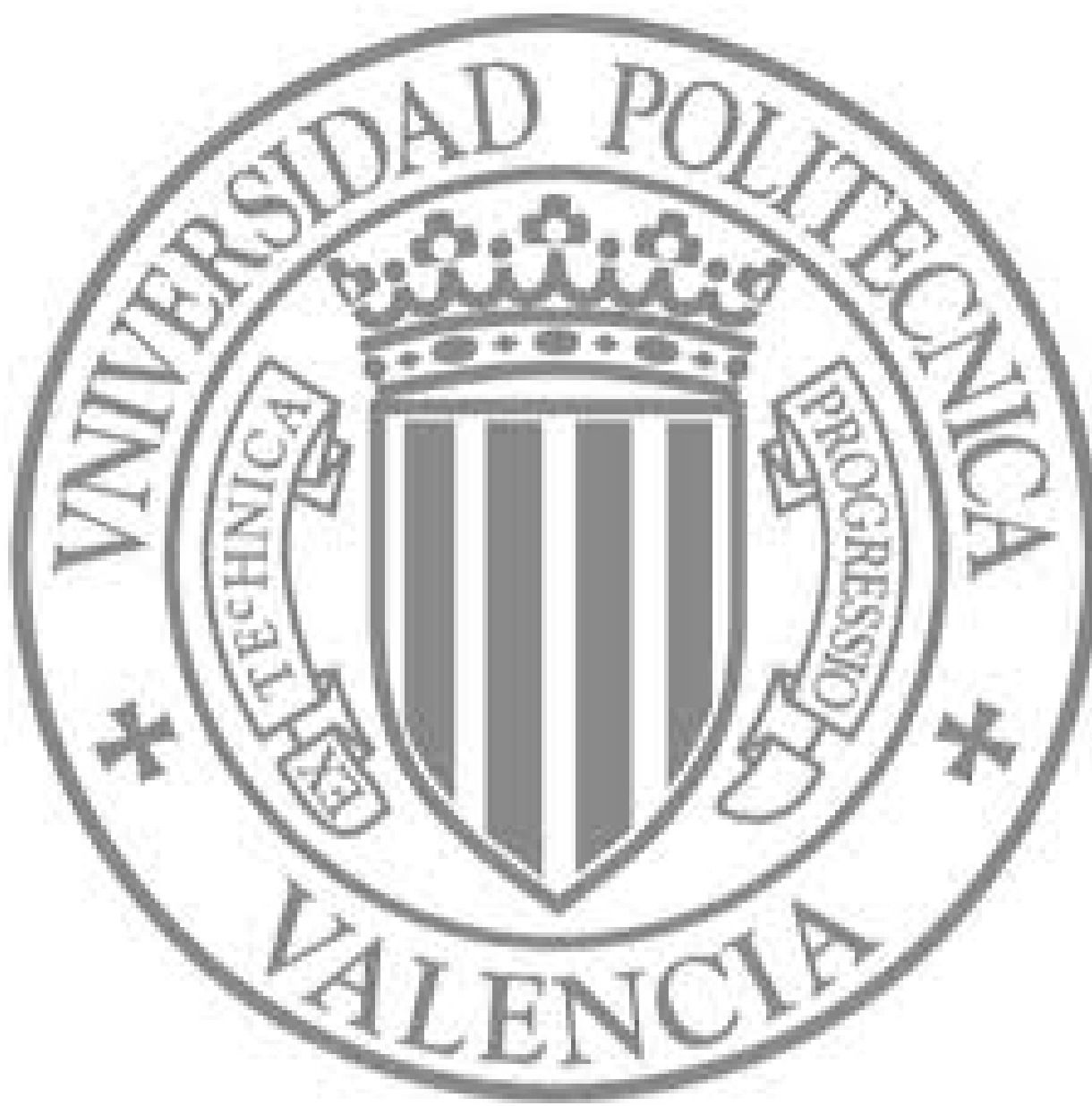

The final publication is available at

http://dx.doi.org/10.1016/j.apenergy.2013.01.027

Copyright Elsevier 


\title{
STUDY LIQUID LENGTH PENETRATION RESULTS OBTAINED WITH A DIRECT ACTING PIEZO ELECTRIC INJECTOR
}

\author{
Raul Payri, Jaime Gimeno, Michele Bardi, Alejandro H. Plazas \\ Correspondig author: Raul Payri rpayri@mot.upv.es
}

\begin{abstract}
A state of the art prototype common rail injector featuring direct control of the needle by means of a piezo stack (direct acting) has been tested. Liquid phase penetration of the sprays in diesel engine-like conditions has been studied via imaging technique in a novel continuous flow test chamber that allows an accurate control on a wide range of thermodynamic conditions (up to $1000 \mathrm{~K}$ and $15 \mathrm{MPa}$ ). This state of the art injector fitted with a 7-hole nozzle, allows a fully flexible control on the nozzle needle movement, enabling various fuel injection rates typology. The temporal evolution of the seven sprays has been studied recording movies of the injection event in evaporative conditions via Mie scattering imaging technique and using a high speed camera. The results showed a strong influence of needle position on the stabilized liquid length while the effect of the injection pressure is negligible: the decrease of the needle lift causes a pressure drop in the needle seat and thus a reduction in the effective pressure upstream of the orifices (in the nozzle sac). According to known literature the stabilized liquid-length depends mainly on effective diameter, spray cone-angle and fuel/air properties and does not depend on fuel velocity at the orifice outlet. Therefore, due to small change in the spray cone-angle, higher injection pressures give slightly lower liquid length. However, partial needle lifts has an opposite effect: when needle is partially lifted a dramatic increase of the spray cone-angle and a consequent reduction of the liquid length are observed. A deeper analysis revealed that low charges are linked also to higher hole to hole dispersion and flow instabilities. Needle vibrations caused by the fuel-needle interactions with fuel flow at partial needle lift and the onset of cavitation in the needle seat are likely the causes of this unexpected behavior. Finally, the effect of injection rate shaping on the transient liquid penetration is presented, showing the capability of the injector to control the liquid length along the injection event. This feature, when applied in a real engine, yields to develop new injection strategies to avoid fuel wall impingement.
\end{abstract}

APPLIED ENERGY; Volume: 106; Pages: 152-162, DOI: 10.1016/j.apenergy.2013.01.027; JUN 2013 


\section{KEY WORDS}

Diesel; injection; spray evaporation; needle control; liquid length

\section{INTRODUCTION}

An important part of the study of the combustion process in Diesel engines is based on spray flow mechanisms because of the importance that they have on engine performance and pollutant emissions [1][2][3][4][5]. Incylinder diesel spray development starts with liquid fuel being injected in an ambient with a certain pressure and temperature. Once injected into the cylinder, the spray changes not only geometrically but also temporally approaching the walls, while it interacts with the surrounding air leading to vaporizing process of the fuel and eventually combustion. Focusing on mixing process, fuel atomization has an important influence on spray local composition, which has an effect on spray penetration and structure [6]. For example, low density conditions could cause liquid impingement on the walls, which may result in unburned hydrocarbons (UHC) and carbon monoxide (CO) emissions; the opposite might cause high combustion rates and hence high in-cylinder local temperature and NOx formation. A compromise between both situations and correct after-treatment techniques are determining factors for current engine performance.

Researchers have performed a lot of studies in order to understand how the mixing process occurs. In such studies the main macroscopic parameters of a spray have been identified as liquid length, vapor penetration, and cone angle [6][7][8][9][10][11]. Experimental facilities such as optically accessible engines [12] and test rig cells [13][14][15][16] have been used for fundamental research of these parameters. Mie-scattering imaging and shadowgraphy are among the most common techniques used to temporally characterize liquid length and vapor penetration, respectively [16]. Throughout the years, basic studies have been made in order to investigate the effects on spray liquid length and vapor phase location induced by engine parameters such as orifice diameter [17], ambient gas conditions [18], injection pressure [19] and fuel characteristics [20][21].

Another important aspect of Diesel combustion is the fuel injection system. Over the past decade several fuel injection systems have been used [1][21][22][23]. All these systems were operated with electro-hydraulic actuation and the injector was activated using either a solenoid or a piezo stack; however, the opening of the injector itself was produced because of a pressure difference at the two sides of the needle.

The last development of piezo-actuated injectors is the so called direct acting system, where a piezo actuator (stack) is mechanically coupled with the injector needle, controlling directly its position: this technologic 
achievement allows a fast and precise control of the fuel flow through the injector nozzle. Although many researchers have been oriented to the study of the injection event using conventional servo-hydraulic injectors, only a few are discussing the effect of the partial needle lift on injection process [25].

The study carried out by Payri et al. in [25] showed the big potential of the direct acting injector in the control of the fuel mass flow rate: in this work they showed how, controlling the needle lift, it is possible to reduce the mass flow rate, obtaining a relationship between needle lift and sac pressure. Adjusting the voltage applied to the piezo-stack, the fuel mass flow rate can be controlled by the electronic control unit (ECU) and injection rate shaping (modulating the mass flow during the injection) is enabled. Both these facts represent a step forward in the capabilities of the injection system and thus in the control of combustion and pollutant emission of a current direct-injection diesel engine. However, the effect of partial needle lift on the spray development and combustion is still not clearly understood: for this reason a full characterization of the injector is required to make the most of it when employed in a real engine.

The first step of this path is an experimental study to capture the liquid phase of the sprays injected by the direct acting injector in evaporative non-reacting conditions. The effect of the partial needle lift has been observed under a wide range of diesel like conditions using a high temperature and high pressure test rig [4]. The facility is capable of reaching $15 \mathrm{MPa}$ ambient pressure and $1000 \mathrm{~K}$ ambient temperature; the large optical accesses and the wide test section allow studying the spray with high accuracy in a homogeneous temperature and nearly quiescent environment. In this work, different parameters have been varied: ambient temperature, ambient pressure, injection pressure and needle lift (piezo stack charge).

\section{MATERIAL AND METHODS}

In this section, the fuel injection system, the high pressure-high temperature test rig and the optical arrangement employed for the tests are described.

\subsection{The fuel injection system}

The fuel feeding to the injector is provided by a common-rail system constituted by a high pressure pump and a conventional rail with a pressure regulator. The system allows fuel injections at high and relatively constant pressure (up to $200 \mathrm{MPa}$ ) [22][23][26]. All the injection system is electronically controlled by the ECU and all the settings are introduced digitally. 
The prototype piezoelectric direct-acting injector is fitted with a 7-hole nozzle with outlet diameter $D_{0}=156$ $\mu m$ and $k$-factor $=1.5[3]$. All the nominal features of the injector are listed in Table 1.

As mentioned before, the piezo actuator is directly coupled with the injector needle and thus, the needle position can be controlled by applying a different voltage to the piezo stack (or piezo stack charge): the needle lift is higher when the voltage applied increases. Being not possible to measure the real needle lift, the hydraulic characterization described in [25] was performed to study the relationship between mass flow rate and piezo stack charge. Although an important reduction in mass flow rate is achieved by means of needle throttling (reducing the piezo-stack charge applied), a quantitative relationship between mass flow rate and piezo stack charge was not found: other parameters were found to affect piezo-stack behavior such as injection pressure and piezo stack temperature. The mass flow rate and the parameters obtained from hydraulic characterization (discharge coefficient $C_{d}$, area coefficient $C_{a}$, and velocity coefficient $C_{v}$ ) [24][25] related to the conditions tested in this work are available from [25].

In order to control the injector temperature a special injector holder was designed to have coolant flowing at constant temperature (about $343 \mathrm{~K}$ ) in direct contact with the injector body. In this study commercial Diesel fuel (EU standard EN590) was used with a density of $812 \mathrm{~kg} / \mathrm{m}^{3}$ and kinematic viscosity of $1.910^{-6} \mathrm{~mm}^{2} / \mathrm{s}$ (at $343 \mathrm{~K}$ ).

\subsection{The High pressure and high temperature test rig}

A novel high temperature and high pressure test chamber capable of mimicking the in-cylinder thermo-dynamic conditions of a Diesel engine at the time of injection has been used. Following the convention presented by Baert in [14] the test rig is classified as constant-pressure flow facility: the high pressure high temperature gas, entering the chamber from a $30 \mathrm{~kW}$ electric heating system, continuously flows through the test chamber. Compared to other facilities [14][27][28] this test rig has the unique feature of obtaining nearly quiescent and steady thermodynamic conditions within the chamber, providing thus an important reduction in the time required for the tests [11][15].

Three large windows (128 $\mathrm{mm}$ in diameter) placed orthogonally give full optical access to the test section. An external view of the combustion chamber is reported in Figure 1. The big size of the test chamber $(200 \mathrm{~mm}$ diameter) and the conical shape of the wall behind the injector nozzle, minimize spray-wall interaction and allow to study spray development in free field-like conditions.

The facility is basically composed of four parts: gas compressors, gas heaters, test vessel and control system. A global sketch of its layout is shown in Figure 2. The gas, stored by volumetric compressors in high pressure reservoirs, flows continuously through the test chamber. Electrical heaters, placed upstream of the chamber, increase the temperature of the gas flowing through the test section at the desired temperature. The control 
system is a closed loop PID that adjusts both, the pressure in the chamber and the power of the heaters to obtain the test conditions required for the experiment. To improve the temperature homogeneity within the test chamber, the vessel has a double wall configuration: while the external walls have the structural function of supporting the pressure of the inner gas, the thinner internal walls are covered with an insulating layer, and have the function of reducing the heat loss toward the outer shell. Moreover, the internal walls are heated by a secondary electrical resistance that surrounds the test chamber: the aim of this heater is to reduce temperature gradients within the testing section. Since the focus of this work is to study spray evaporation, fuel combustion is avoided by recirculating Nitrogen in a closed loop (Figure 2).

\subsection{Optical set-up}

The Mie scattering imaging technique is widely used in spray research for the liquid phase imaging. The technique consists in illuminating the fuel droplets with a light source and imaging the light scattered with a camera. In the literature, several examples of use and calibration of this technique can be found $[1][4][11][27][29]$. The complete theoretical description of the scattering phenomenon is described in [29].

In this work, the sprays have been illuminated by the front window with two continuous Xe-arc lamps and the light scattered backward was collected by a high speed CMOS camera (Phantom v12) aligned with the injector axis. The image size was $512 \times 512$ pixel for a field of view of $70 \times 70 \mathrm{~mm}$, resulting in a spatial resolution of $7.2 \mathrm{pixel} / \mathrm{mm}$. The maximum acquisition rate allowed by the camera at this resolution was 20kfps; a Nikon Nikkor $50 \mathrm{~mm}$ lens with $\mathrm{f} / 1.8$ was used in order to optimize the light collection. The high sensitivity of the camera-lens system and the intensity of the light sources employed gave the possibility to reduce the exposure time to $2 \mu s$, "freezing" the images and obtaining sharper spray boundaries: this feature improves the accuracy of the study and gives a better understanding of spray temporal fluctuations.

Finally, the camera has been positioned in order to have the nozzle at the center of the image, and to have full view of the liquid phase in the whole range of conditions tested. In Figure $1 \mathrm{~b}$ a sketch of the optical setup together with three sample pictures is represented.

\subsection{Image processing}

The image processing is one of the most important steps of the data analysis. Many methods can be found in the literature [11][25][30]. The steps followed in the present work are described below:

- Background subtraction: the image acquired right before the start of injection is arithmetically subtracted to spray images in order to remove reflections and background artifacts. 
- Image division: in order to analyze each spray individually, the image has been divided in 7 sectors as shown in Figure 3.

- Contour detection: the contour of each spray is obtained using the method described by Siebers in [31]. The threshold is calculated as the $3 \%$ of the dynamic range of the sector [31]. Based on this method the images are binarized and the spray contour is obtained.

- Contour analysis: the characteristics of the spray shape are obtained by analyzing its contour. In this work the results are related to two macroscopic characteristics of the spray:

- Maximum liquid penetration $(L L)$ : the spray liquid penetration is calculated as the leading edge of the spray boundary.

- Spreading angle $(\theta)$ : a qualitative description of the spreading angle of the spray is obtained calculating the angle included between the two lines that fit a fixed portion of the spray contour (dashed lines in Figure 4). Even if in other works the part of the contour fitted is scaled with the penetration, for these tests it is preferred to fix it, analyzing only the first $9 \mathrm{~mm}$ from the orifice outlet, where fuel evaporation is considered negligible; in this way the steady liquid length will not have any impact on the spreading angle calculation, providing thus a more robust comparison.

Since some dependence of the results on illumination layout and light intensity should be expected [27], the whole tests were performed without changing any detail of the optical setup, and therefore a good consistency of the results obtained in the different test conditions was assured.

\subsection{Data averaging}

After the transient phenomena at the beginning of the injection, when the spray penetrates in the chamber, the liquid phase penetration stabilizes around a certain distance from the orifice; however, its variations around the average value are significant and are about $25 \%$ of the average value (Figure 5).Therefore, in order to simplify the comparison between different test conditions, an improved rolling average method was used to filter the data.

In each single experiment, a data point $y_{i}$ is obtained at each instant $x_{i}$, time elapsed after the start of the injection. The average value $\mathrm{y}_{\mathrm{m}}$ at the instant $\mathrm{t}_{\mathrm{m}}$ is obtained following the procedure below:

- The data falling in the interval $t_{m} \pm \Delta t / 2$ are considered. An optimal time window $\Delta t=150 \mu s$ has been chosen for the current test.

- A linear regression to the data is performed using the equation below

$$
y=k x+q
$$


- The value of $y_{m}$ is obtained substituting $t_{m}$ in equation 1 .

This algorithm is repeated moving $\mathrm{t}_{\mathrm{m}}$ along the time line with $10 \mu \mathrm{s}$ time step; then the averaged curve is obtained (solid line on Figure 5).

Moreover, in order to have a characteristic value of liquid length and spreading angle for each test condition, the average value $L L_{m}$ and $\theta_{m}$ are calculated averaging the data falling between the time interval $2000-2700 \mu \mathrm{s}$ after start of injection (ASOI). The interval is chosen in order to avoid the transients at the beginning and at the end of injection: in this way the characteristic value obtained is more representative of an ideal steady spray.

In Figure 5, the dots represent the raw experimental data (different colors refer to different sprays) and the black solid line is the average curve. Moreover, in the plot the parameter $L L_{m}$ and the related averaging interval is presented.

\subsection{Test matrix}

In order to have a global picture of the injector behavior, a wide range of test conditions has been explored. The test matrix has been designed to investigate the general behavior of the injector, but also to understand the effect of partial needle lift on the liquid length during the steady part of the injection as well in the first transient when the spray starts penetrating in the chamber. The test plan (Table2) has been performed varying the ambient temperature, gas pressure, injection pressure and needle lift. The test matrix aims to reach two objectives: to target thermodynamic conditions relevant to the current Diesel engines and to obtain a well-defined picture of the parameters that affect the phenomenon studied. For this second reason, boundary conditions vary between significantly different values.

As explained before, the needle lift is controlled adjusting the piezo stack voltage (charge) [25]: no clear relationship was found between the needle lift and the charge applied, for this reason the three needle lift tested are qualitatively referred as low, med and high charge. High charge corresponds to the full needle lift case when injector needle effect on fuel flow is considered to be very small, while at med and low charge the needle lift is progressively reduced, and therefore the related mass flow rate. 


\section{RESULTS}

Several works found in the literature show that the parameters affecting liquid length are normally ambient density, ambient temperature, fuel temperature and just in a minor degree, injection pressure [15][23][25]. In the next sections the effect on $L L$ related to these test conditions is presented together with the effect of partial needle lift.

In Figure 6 and Figure 7, the 7-spray average liquid phase penetration is plotted. In the plots the characteristic shape of liquid phase penetration in evaporative conditions can be observed: in a first period the sprays penetrated in the test chamber until a certain distance is reached. At that distance, the enthalpy of the entrained gas is enough to evaporate all the fuel, and liquid phase maximum penetration oscillates around an average value.

In Figure 6 the liquid phase penetration at two ambient temperatures is shown for the high charge case (maximum needle lift) at $150 \mathrm{MPa}$. In the lower part of the figure is also plotted the mass flow rate measured with the Bosch method [25][32] for a better understanding of the data. As expected both curves overlap in the first transient part, since ambient density is very similar in the two cases but it stabilizes at different values as a consequence of the higher temperature of the ambient gas.

The comparison drawn in Figure 7 shows liquid phase penetration at two different injection pressures, and presents an opposite scenario: during the transient part, higher injection pressure contributes to a faster penetration, as a consequence of a higher velocity at the orifice outlet. On the other hand the effect on the steady $L L$ is negligible.

When ambient pressure is varied keeping constant the temperature the effect of gas density on the spray can be observed: as shown in Figure 8, liquid phase penetrations is reduced in both, the transient and the steady period. The spray penetration is lower at higher ambient density; two factors are contributing to this result:

- The spreading angle has been experimentally observed to increase at higher ambient densities, increasing the volume of hot gas entrained in the spray.

- The higher density of the volume of gas entrained requires more kinetic energy to complete the momentum transfer, and thus the spray penetrates lower.

Both factors above cause the reduction of penetration speed and of the liquid length observed when ambient density is increased. 
All the effects described above are already known and they are described in the literature. However, these comparisons are important because they give a quantitative guidance for a future use of the injector in a real engine and at the same time they confirm the reliability of the experimental methodology employed.

In the plots presented from Figure 6 to Figure 8, liquid length always shows a slight positive slope, at the steady period mentioned before. As discussed by other authors [4][33], there are two factors that likely contribute to this effect: the temperature of the fuel at the beginning of the injection is higher because the injector sac is continuously in direct contact with the high temperature gas of the test chamber; during the injection the fuel flowing from upstream of the sac cools down the injector tip. In this way the temperature of the fuel at the orifice outlet is decreasing during the injection and this fact is reflected on liquid length [4]. The second possible cause is that, for long injections, low temperature fuel-air mix is re-entrained in the spray causing thus, a decrease in the effective ambient temperature and an increment in liquid length. Considering the large size of the chamber and that the slope seems to decrees at the end of the injection, authors consider the first possibility the most likely cause for the phenomenon observed.

For a global comparison of the data, the parameter $L L_{m}$ has been plotted versus ambient temperature and ambient density respectively in Figure 9 and Figure 10. Figure 9 shows that the effect of injection pressure is negligible at full needle lift; moreover, an increase in $T_{a m b}$ at full needle lift has the same effect in reducing $L L_{m}$ at both injection pressures. On the other hand when the charge applied to the piezo-stack is reduced two main effects are evident:

- Injection pressure is affecting $L L m$, and moreover ambient temperature effect is quantitatively different at different $P_{\text {rail }}$. This can be explained by the impact that the variation of these boundary conditions have on injector behavior (rather than on spray development): injection pressure is causing the compression of the needle, and this compression is changing depending on $P_{\text {rail }}$ and having an effect on the fuel flow; moreover, even if a special device for injector temperature control is used, ambient temperature is somehow affecting the temperature of the injector, and thus of the piezo-stack. For this reason the needle lift is not exactly the same when test conditions are changed.

- Reducing needle lift, spray liquid length is significantly reduced. If partial needle lift effect is considered just as fuel flow throttling upstream of the nozzle sac, the only consequence expected would be a reduction in the fuel pressure upstream of the orifice; in this case the effect on liquid length should be the same observed when injection pressure is reduced. However, the important reduction in liquid length caused by partial needle lift means that internal flow is somehow changing and this is affecting the spray development. 
Figure 10 remarks the same point: a reduction in needle lift causes a significant reduction in liquid length even at different ambient density. The effect of needle lift on spray development is discussed in detail in the next section as it is one of the new findings presented in this research work.

\section{DISCUSSION}

The 7-spray average liquid phase penetration is plotted in Figure $11 a$ and Figure $11 b$ for two different ambient temperatures. In both cases the effect of needle lift is appreciated during the spray penetration and during the "steady" part of the injection when liquid length stabilizes: at lower needle lift spray penetrate slower and LLm is shorter. This fact confirms, as discussed before, that some change in the internal flow is affecting spray development downstream of the orifice.

In order to compensate the lack of quantitative information about the needle lift, a non-dimensional parameter has been introduced and it is defined in equation (2) [25]:

$$
\lambda=\frac{\dot{m}}{\dot{m}_{f . n . l .}}
$$

Where $\dot{m}$ is the average mass flow rate for a specific charge level and $\dot{m}_{f . n . l .}$ is the average mass flow rate at same injection pressure but at full needle lift (high charge level). Observing Figure 12a, a linear relationship seems to link $\lambda$ and $L L_{m}$ and the liquid length penetration is reduced as the injector needle throttles the flow. This relationship is consistent even when injection pressure is changed, creating a link between the results observed in Figure 9. Parameter $\lambda$ seems to control the value of steady $L L_{m}$. On the other hand, the spreading angle $\theta_{m}$ shows a coherent increase when needle lift is reduced (Figure 12b) providing further information about the modifications in spray development.

In order to understand the phenomenon, the spray model developed by Pastor et al [34] has been employed. The model is based on the mixing driven evaporation assumption and for a given ambient condition the liquid length is determined by equation (3):

$$
L L_{t h}=\frac{K_{p}^{2} \cdot C_{a}^{\frac{1}{2}} \cdot D_{o}}{C_{m v} \cdot \tan \left(\frac{\theta}{2}\right)} \sqrt{\frac{\rho_{f}}{\rho_{a m b}}}
$$


Where $K_{p}$ is a constant depending on ambient conditions, $C_{a}$ is the area coefficient, $D_{0}$ is the orifice diameter, $C_{m v}$ is a coefficient depending on the fuel and ambient properties, $\theta$ the spreading angle, $\rho_{f}$ and $\rho_{a m b}$ are respectively fuel and air density.

The equation above gives the important advantage of relating directly liquid length on spreading angle $\theta$ and area coefficient $C_{a}$ that are the only parameters affected by the partial needle lift. Moreover, both parameters have been directly measured: the angle $\theta$ in the current work, while $C_{a}$ was obtained from the hydraulic characterization carried out in [25].

To understand if the relationship between charge level and $L L$ can be explained by the variation of these two parameters, a theoretical liquid length $\left(L L_{t h}\right)$ has been calculated using the equation (4) and scaling the liquid length obtained experimentally at full needle lift with the values of $C_{a}$ and the spreading angle $\theta_{m}$ obtained at medium and low charge. The remaining coefficients $\left(K_{p}, D_{0}, C_{m v}, \rho_{f}\right.$ and $\left.\rho_{a m b}\right)$ do not change when $T_{a m b^{-}} P_{i n j}$ values are the same. Thus $L L_{t h}$, for each $T_{a m b}-P_{\text {rail }}$, can be written as follows:

$$
L L_{t h}=L L_{m, f . n . l .}\left(\frac{C_{a}}{C_{a, f . n . l .}}\right)^{1 / 2} \cdot \frac{\tan \left(\frac{\theta_{m, f . n . l .}}{2}\right)}{\tan \left(\frac{\theta_{m}}{2}\right)}
$$

Where the sub index f.n.l. refers to the full needle lift case (high charge). In Figure 13 the results of the calculation are plotted for all the variations in needle lift tested: the comparison between experimental and theoretical result remarks that the variation in spreading angle and area coefficient can reproduce the trend observed in the experiments. However, the variations predicted by the formula do not agree completely with the experimental data. One cause might be that the technique employed for the angle detection and calculation is not considering the vapor phase of the spray, and, even if in the region of the spray considered for the angle calculation fuel evaporation is very close to the orifice outlet, part of the spray might be missed. In fact, the spreading angle used in the theoretical model (equation 4) should also include the region of the spray contour where the fuel mass fraction is very low. This angle can be obtained by Schlieren imaging, or the most complex Rayleigh scattering as discussed in [29]. However, even with a very accurate diagnostic like Rayleigh scattering imaging, the definition of the spreading angle might be not enough representative of the whole spray shape. The angle employed in this work (obtained by means of Mie scattering imaging in evaporative conditions) is suitable only for a qualitative evaluation of the results. 
Despite the calculations performed shows that the reduction in liquid length due to partial needle lift relates to variations in spreading angle and area coefficient with relative good accuracy, more analysis is needed to understand the complete picture of the problem.

In Figure 14 the penetration obtained for each spray is plotted on the same graph for two different needle lift. The plot shows that when needle lift is reduced the hole to hole dispersion increases in two ways: spray penetration rate during the first transient period of the injection; and liquid lengths during the stabilized period. This information is summarized in the polar plots in Figure 15: in the case of high charge (full needle lift), no significant difference is observed in the behavior of the different sprays in term of stabilized $L L$ (less than $10 \%$ dispersion of the seven sprays on the average $L L$ ). This hole-to-hole spread measured is considered to fall in the range of the uncertainty due to small inhomogeneity of the illumination field: Mie scattering technique, as most of the other methodology to detect $L L$, is very sensitive to the illumination employed [27]. On the other hand, when piezo-stack charge is decreased, the spray symmetry is broken, and some of the sprays shorten more than others.

It is important to underline that the results presented are calculated over six repetitions: this means that the holeto-hole dispersion observed is not due to a statistical behavior of the flow, but it is repetitive. This result might support the thesis that some consistent asymmetry characterize the flow in the nozzle sac when needle lift is reduced, causing an uneven distribution of the fuel through the orifices and differences in the sprays. Again, the fuel pressure in the nozzle sac is not the only driving parameter for the spray development.

A further analysis has been carried out reducing the visualization window of the camera to only one spray in order to obtain a higher frame rate $(68 \mathrm{kfps})$ and try to track more features of the spray. The higher time resolution of the test allowed to observe the temporal fluctuation of the liquid length. A further feature has been extracted from images measuring the spray width at $9 \mathrm{~mm}$ from the orifice outlet: this measurement has been preferred to spreading angle because it provides a better response to the temporal fluctuations in the spray: in fact, the spreading angle measurement is evaluating the first $9 \mathrm{~mm}$ of the spray contour, and for this reason it is smoothing spray's fluctuations.

In Figure 16a liquid penetration and spray width results are plotted. In order to understand the temporal fluctuation of the measurements, the data presented are related to only one injection event. The plot on one side confirms the effect of the charge previously observed: when charge is decreased, liquid length is shorter and wider (spray width is easy to relate with spreading angle); on the other side, it shows that when needle lift is throttling, the spray behavior is less steady, showing higher fluctuations around an average value especially over spray width. Figure $16 \mathrm{~b}$ gives a further confirmation of the unsteadiness of the flow: two images acquired at 
$2000 \mu \mathrm{s}$ ASOI are compared for two different charges. Even if it cannot be considered a quantitative measurement, the distribution of the scattered light intensity suggests that at lower charge the axial distribution of the fuel in the spray is less homogeneous: this can be considered a further insight of unsteadiness in the fuel flow.

Putting together all the insight found, the effects observed can be related to two facts:

- The interaction between the fuel flow and the injector needle are causing the needle itself to vibrate. These vibrations that have been already related to fluctuation in fuel flow [35][36], might be at the origin of the modifications in the spray structure observed.

- The onset of cavitation in the needle seat. Several studies demonstrated that fuel cavitation within the orifice is linked with an increase of the spray spreading angle [21][37]. Moreover, it is usually described a transient regime of the cavitation, that proceed the flow collapse. In this regime fuel vapor is not formed continuously and vapor bubbles are formed statistically.

Both phenomena concur in modifying the spray development and are both consistent with all the observation done in this work.

The significant effect that partial lift has on liquid phase penetration can thus be a useful tool for the development of new engine strategies. The electronic control of the needle lift guarantees a very fast response of the injector and allows the innovative feature of rate shaping: the mass flow rate as well as the needle opening can be controlled. In this scenario, also liquid length can be controlled and varied during the injection as a consequence of rate shaping. To reduce the mass flow rate in the first part of the injection by reducing the needle lift would have a double positive effect: the mass of fuel injected before the ignition would be decreased, reducing the problems related to the premixed combustion; moreover, the wall impingement, before the ignition, would be reduced as a consequence of a shorter liquid length.

\section{CONCLUSIONS}

The liquid phase penetration of a prototype multi orifice direct acting injector has been characterized for the first time in a wide range of test conditions in a novel high temperature high pressure test rig.

The experimental results presented are consistent with the $L L$ dependency with $T_{a m b}$ and $P_{\text {rail }}$ found in the literature. Furthermore, an interesting relationship was found between steady liquid length $\left(L L_{m}\right)$ and charge level (needle lift). 
It is not correct to consider partial needle lift effect only as a pressure drop upstream of the nozzle sac, because it is not coherent with the results obtained: in that case, the expected effect on the spray should be the same as a reduction in injection pressure, causing a slower spray penetration and a negligible difference in liquid length. What observed experimentally in this work confutes this hypothesis. It has been experimentally observed that a reduction in needle lift causes:

- A significant reduction in liquid length

- An increment in the spreading angle

- A slight reduction of area coefficient

- An increase in the hole-to-hole dispersion, in terms of penetration of liquid length

- Higher oscillations in spray width and liquid length. This fact suggests the presence of significant fluctuations in the fuel mass flow rate through the orifices as a result of partial needle lift.

Considering that when needle lift is reduced, no effect is expected on chamber conditions, a significant modification in the internal flow is considered to take place in the nozzle sac, and to affect the spray development. More precisely, in the authors' opinion, the partial needle lift is causing two phenomena that contribute in modifying the mixing process and reducing liquid length:

- The onset of cavitation in the needle seat: the section restriction caused by partial needle lift can cause cavitation in the same way as it happens for low k-factor nozzle orifice. In this case the vapor formed would contribute in a reduction on the $C_{a}$ as well as an increase in the spreading angle as described in [37]

- Fluctuations in the fuel mass flow rate as a consequence of needle vibration. Also in this case the unsteadiness in the flow could affect the spray development and enhance air entrainment and thus the evaporation of the fuel.

The relationship between liquid length, spreading angle and area coefficient has been verified using a 0-D model for spray description and the analysis revealed a good agreement between the theoretical relationship and the experimental data.

The effect of needle lift on liquid length is potentially a powerful tool for engine designers to avoid wall impingement.

\section{ACKNOWLEDGMENT}

This work was sponsored by General Motors R\&D, Warren, MI. The authors would like to thank Jose Enrique del Rey and David Fuertes Muñoz for their precious work in the laboratory during the tests. 


\section{BIBLIOGRAFY}

[1] Catania, A. E. Ferrari, A Development and performance assessment of the new-generation CF fuel injection system for diesel passenger cars, APPLIED ENERGY, Vol 91 (1), pp. 483-495, 2012

[2] Park Su Han; Yoon Seung Hyun; Lee Chang Sik, Effects of multiple-injection strategies on overall spray behavior, combustion, and emissions reduction characteristics of biodiesel fuel, APPLIED ENERGY, Vol 88 (1) pp. 88-98, 2011

[3] Payri, R., Salvador, FJ; Gimeno, J. and De la Morena, J., Effects of nozzle geometry on direct injection diesel engine combustion process, Applied Thermal Engineering, pp. 2051-2060, vol. 29, 2009.

[4] Payri, R., Garcia-Oliver, J.M., Bardi, M, Manin, J., Fuel temperature influence on diesel sprays in inert and reacting conditions, Appl Therm Eng 2012;35:185-195

[5] Som, S Ramirez, A.I., Longman, D.E., Aggarwal, S.K., Effect of nozzle orifice geometry on spray, combustion, and emission characteristics under diesel engine conditions, FUEL 90 (3), pp. 1267-1276, 2011

[6] Payri, R., Tormos, B., Salvador, FJ, Araneo, L., Spray Droplet Velocity Characterization For Convergent Nozzles With Three Different Diameters, Fuel, pp. 3176 - 3182, vol. 87, 2008.

[7] Som, S.; Aggarwal, SK. Effects of primary breakup modeling on spray and combustion characteristics of compression ignition engines, Combustion and flame, Vol 157 (6), pp. 1179-1193, 2010

[8] Gao, J., Matsumoto, Y., and Nishida, K., Experimental study on spray and mixture properties of the group hole-nozzle for direct-injection diesel engines. Part I: A comparative analysis with the single hole nozzle, Atomization Sprays, vol. 19,pp. 321-337, 2009

[9] Klein-Douwel, R., Frijters, P., Somers, L., de Boer, W., and Baert, R., Macroscopic diesel fuel spray shadowgraphy using high speed digital imaging in a high pressure cell, Fuel,vol. 86, pp. 1994-2007, 2007

[10] Payri, R., Salvador, F., Gimeno, J., and Zapata, L., Diesel nozzle geometry influence on spray liquidphase fuel penetration in evaporative conditions, Fuel, vol. 87, pp. 1165-1176, 2008

[11] Bardi, M., Payri, R., Malbec, L-M., Bruneaux, G., Pickett, L. M., Manin, J., Genzale, C., Bazyn, T., Engine Combustion Network (ECN): Comparison of Spray Development, Vaporization and Combustion in Different Combustion Vessels, Atomization and Sprays, doi: 10.1615/AtomizSpr.2013005837.

[12] Genzale, C.L., Reitz, R.D., Musculus, M.P.B., Effects Of Spray Targeting On Mixture Development And Emissions Formation In Late-Injection Low-Temperature Heavy-Duty Diesel Combustion, Proceedings of the Combustion Institute, pp. 2767-2774, vol. 32, 2009.

[13] Kook, S., Pickett, L.M., and Musculus, M. P., Influence of diesel injection parameters on end-ofinjection liquid length recession, SAE Tech. Pap. 2009-01-1356, 2009

[14] Baert, R., Frijters, P., Somers, B., Luijten, C., Design and operation of a high pressure, high temperature cell for HD diesel spray diagnostics: guidelines and results, SAE Paper 2009-01-0649, 2009.

[15] Meijer, M., Nesbitt, J., Pickett, L. M., Malbec, L-M, Bruneaux, G., Bardi, M., Payri R. and Bazyn, T., Engine Combustion Network (ECN): Characterization and comparison of boundary conditions for different combustion vessels, Atomization and Sprays, 2012;22(9):777-806.

[16] Soid S.N.; Zainal Z. A., Spray and combustion characterization for internal combustion engines using optical measuring techniques - A review, ENERGY, Volume: 36 (2), pp 724-741, 2011

[17] Siebers D.L., Liquid-Phase Fuel Penetration in Diesel Sprays, SAE Paper 980809, 1998 
[18] Roisman, I., Araneo, L., and Tropea, C., Effect of ambient pressure on penetration of a diesel spray, Int. J. Multiphase Flow, vol. 33, pp. 904-920, 2007

[19] Naber, J. D. and Siebers, D. L., Effects of gas density and vaporization on penetration and dispersion of diesel sprays, SAE Tech. Pap. 960034, 1996

[20] Pastor, J., Payri, R., Gimeno, J., and Nerva, J., Experimental study on RME blends: Liquid-phase fuel penetration, chemiluminescence, and soot luminosity in diesel-like conditions, Energy Fuel, vol. 23, pp. 5899-5915, 2009.

[21] Myong K, Arai M, Suzuki H, Senda J, Fujimoto H., Vaporization Characteristics and Liquid-Phase Penetration for Multi-Component Fuels, SAE 2004-01-0529, 2004

[22] Payri, R., Salvador, F.J., Gimeno. J., De la Morena, J., Influence of injector technology on injection and combustion development - Part 1: Hydraulic characterization, Appl. Energy, pp. 1068-1074, 2011

[23] Payri, R., Salvador, F.J., Gimeno. J., De la Morena, J., Influence of injector technology on injection and combustion development - Part 2: Combustion analysis, Appl. Energy, Vol 88 (4), pp. 1130-1139, 2011

[24] Lichtarowicz, A.K., Duggins, R.K., Markland, E., Discharge coefficients for incompressible noncavitating flow through long orifices”, Journal of Mechanical Engineering Science, Vol. 7 (2), 1965.

[25] Payri, R., Gimeno, J., Venegas, O., Plazas, A.H., Effect of Partial Needle Lift on the Nozzle Flow in Diesel Fuel Injectors, SAE 2011-01-1827, 2011

[26] Som, S., Aggarwal, S.K., El-Hannouny, E.M., Longman, D.E, Investigation of Nozzle Flow and Cavitation Characteristics in a Diesel Injector, Journal Of Engineering For Gas Turbines And PowerTransactions Of The ASME, Vol 132 (4), 2010

[27] Pickett, L., Genzale, C.L., Manin, J., Malbec, L-M, Hermant, L., Measurement Uncertainty of Liquid Penetration in Evaporating Diesel Sprays, ILASS2011-111, 2011

[28] Parrish, S. E., Zink, R., Development and application of an imaging system to evaluate liquid and vapor envelopes of sprays from a multi-hole gasoline fuel injector operating under engine-like conditions, ILASS2011-170, 2011

[29] Pickett, L.; Manin, J.; Genzale, C.; Siebers, D.; Musculus, M., Idicheria, C., Relationship Between Diesel Fuel Spray Vapor Penetration/Dispersion And Local Fuel Mixture Fraction, SAE Paper 2011-010686, SAE International Journal of Engines, 2011

[30] Macian, V., Payri, R., Garcia, A., Bardi, M., Experimental Evaluation of the Best Approach for Diesel Spray Images Segmentation, Experimental Techniques 2012; 36(6):26-34

[31] Siebers, D.L., Scaling Liquid-Phase Fuel Penetration In Diesel Sprays Based On Mixing-Limited Vaporization, SAE -1999-01-0528, 1999

[32] Payri, F., Salvador, F.J., Gimeno, J., Bracho, G. A new methodology for correcting the signal cumulative phenomenon on injection rate measurements. Experimental Techniques, 32(1), pp. 46-49, 2008

[33] Pickett, L., M., Genzale, C., Bruneaux, G., Malbec, L.-M., Hermant, L., Christiansen, C., Schramm, J., Comparison of diesel spray combustion in different high-temperature, high pressure, facilities, SAE international, SAE2010-01-2106, 2010.

[34] Pastor, J.V., Lopez, J.J., Garcia-Oliver, J.M., Pastor, J.M., A 1D model for the description of mixingcontrolled inert diesel sprays, Fuel, Volume 87, Issues 13-14, Pages 2871-2885, 2008.

APPLIED ENERGY; Volume: 106; Pages: 152-162, DOI: 10.1016/j.apenergy.2013.01.027; JUN 2013 
[35] Powell, CF and Kastengren, AL and Liu, Z. and Fezzaa, K., The Effects of Diesel Injector Needle Motion on Spray Structure, Journal of Engineering for Gas Turbines and Power, vol. 133, 2011.

[36] Manin J, Kastengren A.L., Payri R, Understanding the Acoustic Oscillations Observed in the Injection Rate of a Common-Rail Direct Injection Diesel Injector. Journal of Engineering for Gas Turbines and Power 2012;134(12):122801.

[37] Payri, F., Bermúdez, V., Payri, R., Salvador, F.J., The influence of cavitation on the internal flow and the spray characteristics in diesel injection nozzles, Fuel 83, pp. 419-431, 2004

\section{NOTATION}

$\begin{array}{ll}\text { ASOI } & \text { After the start of injection } \\ \mathrm{BP} & \text { Back pressure } \\ \mathrm{C}_{\mathrm{d}} & \text { Discharge coefficient } \\ \mathrm{C}_{\mathrm{a}} & \text { Area coefficient } \\ \mathrm{C}_{\mathrm{m} . \mathrm{v} .} & \text { Constant defined in } 4 \\ \mathrm{C}_{\mathrm{v}} & \text { Velocity coefficient } \\ \mathrm{Ch} & \text { Piezo stack charge level } \\ \mathrm{D}_{0} & \text { Orifice outlet diameter } \\ \mathrm{ECU} & \text { Electronic control unit } \\ f . n . l & \text { Full needle lift } \\ \mathrm{k} & \text { Linear regression constant } \\ \mathrm{Kp}_{\mathrm{p}} & \text { Constant defined in } 4 \\ \mathrm{LL}_{\mathrm{L}} & \text { Liquid phase penetration } \\ \mathrm{LL}_{\text {th }} & \text { Theoretical steady liquid length } \\ \mathrm{LL}_{\mathrm{m}} & \text { Average liquid length } \\ \dot{m} & \text { Mass flow rate } \\ \mathrm{P}_{\text {rail }} & \text { Rail fuel pressure } \\ \mathrm{T}_{\mathrm{amb}} & \text { Ambient Temperature } \\ \mathrm{T}_{\mathrm{f}} & \text { Coolant temperature } \\ \mathrm{q} & \text { Linear regression contant }\end{array}$

APPLIED ENERGY; Volume: 106; Pages: 152-162, DOI: 10.1016/j.apenergy.2013.01.027; JUN 2013 
t Time

$\mathrm{x}_{\mathrm{i}} \quad$ Time related to the raw datum

$\mathrm{y}_{\mathrm{i}} \quad$ Raw datum

$\lambda \quad$ Parameter defined in section 4

$\Delta \mathrm{t} \quad$ Time window for data averaging

$\rho_{\mathrm{amb}} \quad$ Ambient density

$\rho_{\mathrm{f}} \quad$ Fuel density

$\theta_{\mathrm{m}} \quad$ Spreading angle

APPLIED ENERGY; Volume: 106; Pages: 152-162, DOI: 10.1016/j.apenergy.2013.01.027; JUN 2013 


\section{LIST OF TABLES}

\begin{tabular}{cc}
\multicolumn{2}{c}{ Injector features } \\
\hline Brand & Continental \\
Nozzle seat type & micro-sac \\
Number of orifices & 7 \\
Spray included angle & $158^{\circ}$ \\
Outlet diameter & $0.152 \mathrm{~mm}$ \\
$k$ - factor & 1.5 \\
Discharge coefficient & 0.81 \\
\hline
\end{tabular}

Table 1: Injector Features. Nominal characteristics of the Continental direct acting injector.

\begin{tabular}{ccc} 
Parameters & Values & Unit \\
\hline Fuel & Commercial Diesel & - \\
Energizing time & 3000 & $\mu \mathrm{s}$ \\
Coolant temperature $\left[\mathrm{T}_{\mathrm{f}}\right]$ & 343 & $\mathrm{~K}$ \\
Gas pressure $[\mathrm{BP}]$ & $3.5-5.0-6.5$ & $\mathrm{MPa}$ \\
Gas temperature $\left[\mathrm{T}_{\text {amb }}\right]$ & $870-950$ & $\mathrm{~K}$ \\
Injection pressure $\left[\mathrm{p}_{\text {rail }}\right]$ & $60-150$ & $\mathrm{MPa}$ \\
Piezo stack charge $[\mathrm{Ch}]$ & low - med -high & - \\
Oxygen concentration & 0 & $\%$ (vol.) \\
\hline
\end{tabular}

Table2: Test matrix.

APPLIED ENERGY; Volume: 106; Pages: 152-162, DOI: 10.1016/j.apenergy.2013.01.027; JUN 2013 


\section{LIST OF CAPTIONS}

Figure 1: Optical Setup. a) Picture of the optical setup employed in the tests. b) Scheme of the experimental layout.

Figure 2: General lay-out of the high pressure and high temperature facility. The close loop Nitrogen circuit is represented together with the control system and the injector temperature control system.

Figure 3: Sectorization of the image. Every sector (delimited by the solid line) is processed separately.

Figure 4: Spray boundary processing. The liquid phase penetration and the spreading angle definition are presented. The dashed lines indicate the result of the fit to the spray contour performed for the spreading angle calculation.

Figure 5: Averaging Method. For sample test the result of the averaging method is compared to the experimental data. On $X$ axis is reported the time elapsed after the start of the injection (ASOI). The dots represent the experimental data (different colors refer to different sprays) and the black solid line is the average curve. In the plot is presented also the parameter $L L_{m}$ and the related averaging interval.

Figure 6: Effect of ambient temperature on the liquid phase penetration. $P_{\text {rail }}=150 \mathrm{MPa}, \mathrm{BP}=5 \mathrm{MPa}, \mathrm{Ch}=\mathrm{high}$.

Figure 7: Effect of injection pressure on the liquid phase penetration. $T_{a m b}=950 \mathrm{~K}, \mathrm{BP}=5 \mathrm{MPa}, \mathrm{Ch}=\mathrm{high}$.

Figure 8: Effect of ambient density on the liquid phase penetration. $T_{a m b}=870 \mathrm{~K}, P_{\text {rail }}=60 \mathrm{MPa}, \mathrm{Ch}=\mathrm{high}$.

Figure 9: Effect of ambient temperature on the parameter LLm. BP $=5 \mathrm{MPa}$.

Figure 10: Effect of ambient density on the parameter $L L_{m} . T_{a m b}=870 \mathrm{~K}, P_{i n j}=60 \mathrm{MPa}$.

Figure 11: Effect of charge level on liquid phase penetration. a) $T_{a m b}=870 \mathrm{~K}, P_{\text {rail }}=150 \mathrm{MPa}, \mathrm{BP}=5 \mathrm{MPa}$; b) $T_{a m b}=950 \mathrm{~K}, P_{\text {rail }}=$ $150 \mathrm{MPa}, \mathrm{BP}=5 \mathrm{MPa}$.

Figure 12: Effect of $\lambda$. Average liquid length $L L_{m}(\mathrm{a})$ and average spreading angle $\theta_{\mathrm{m}}(\mathrm{b})$ versus parameter $\lambda, B P=5 M P a$.

Figure 13: Model comparison. $L L_{m}$ experimental and $L L_{t h}$ obtained by equation (4) versus the parameter $\lambda$ at a) $P_{\text {rail }}=60 M P a$ and b) $P_{\text {rail }}=150 \mathrm{MPa}, \mathrm{BP}=5 \mathrm{MPa}$.

Figure 14: Effect of charge level on hole-to-hole dispersion. $T_{a m b}=950 \mathrm{~K}, P_{\text {rail }}=150 \mathrm{MPa}, \mathrm{BP}=5 \mathrm{MPa}$.

Figure 15: Effect of charge level on hole-to-hole dispersion. a) $P_{\text {rail }}=60 \mathrm{MPa}$ and b) $P_{\text {rail }}=150 \mathrm{MPa}$ : LLm is plotted for each spray. $T_{a m b}=950 \mathrm{~K}, \mathrm{BP}=5 \mathrm{MPa}, \mathrm{BP}=5 \mathrm{MPa}$.

Figure 16: Spray Temporal fluctuations. a) spray penetration and spray width at $9 \mathrm{~mm}$ from the outlet obtained for just one repetition and b) images of one of the quasi-steady sprays at two different charge level. $P_{\text {rail }}=60 \mathrm{MPa}, T_{\mathrm{amb}}=870 \mathrm{~K}, \mathrm{BP}=5$ MPa. 
a)

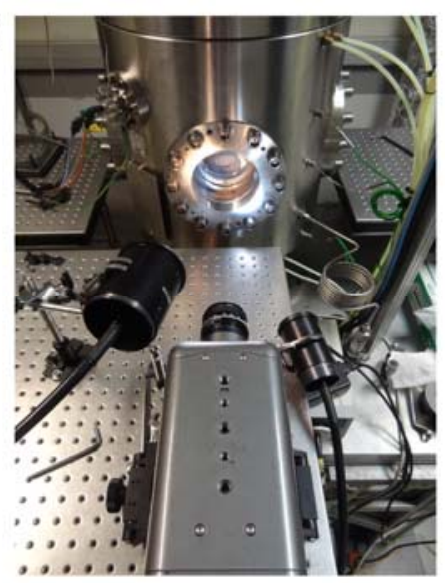

b)

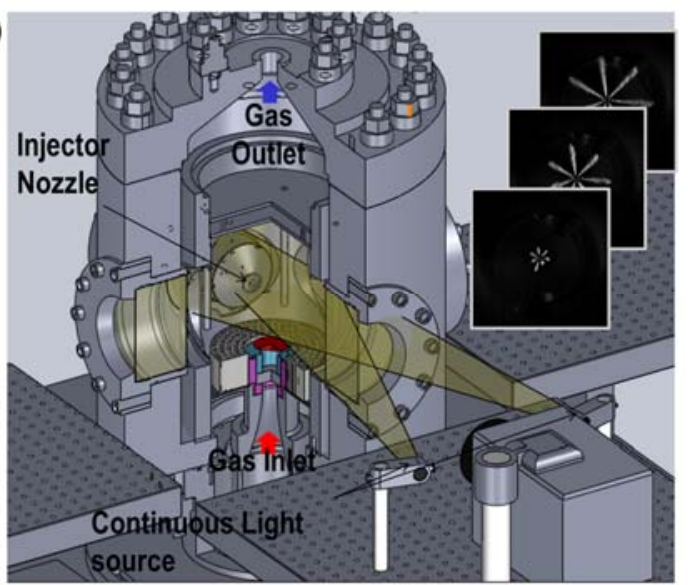

Fig 1

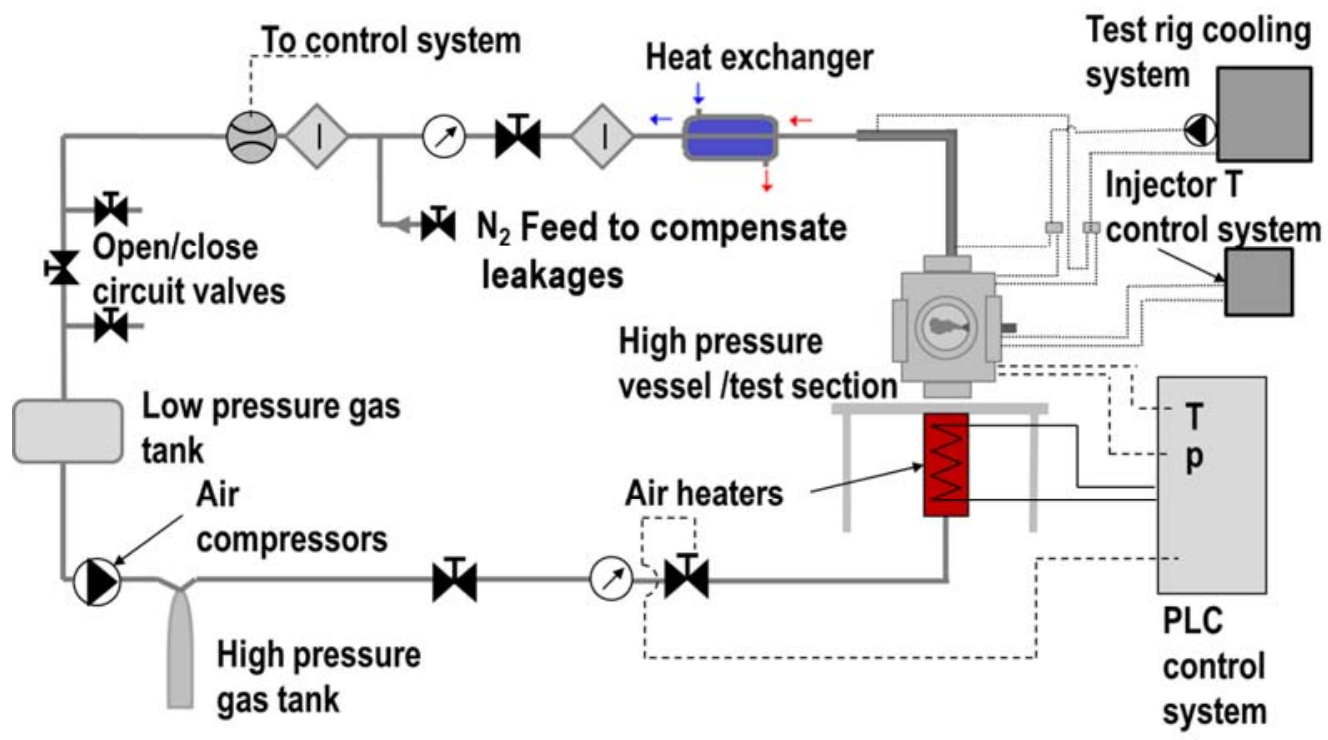

Fig 2

APPLIED ENERGY; Volume: 106; Pages: 152-162, DOI: 10.1016/j.apenergy.2013.01.027; JUN 2013 


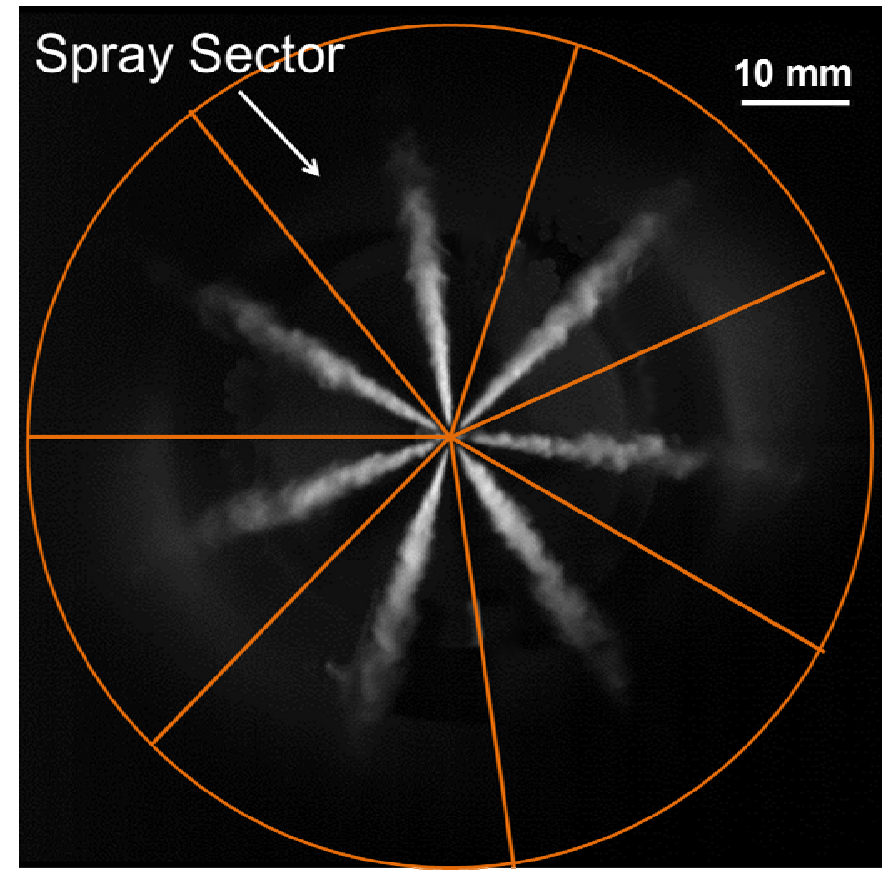

Fig 3

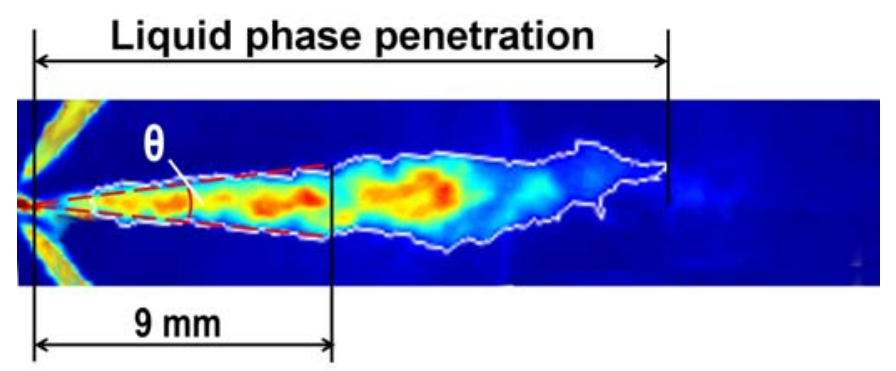

Fig 4

APPLIED ENERGY; Volume: 106; Pages: 152-162, DOI: 10.1016/j.apenergy.2013.01.027; JUN 2013 


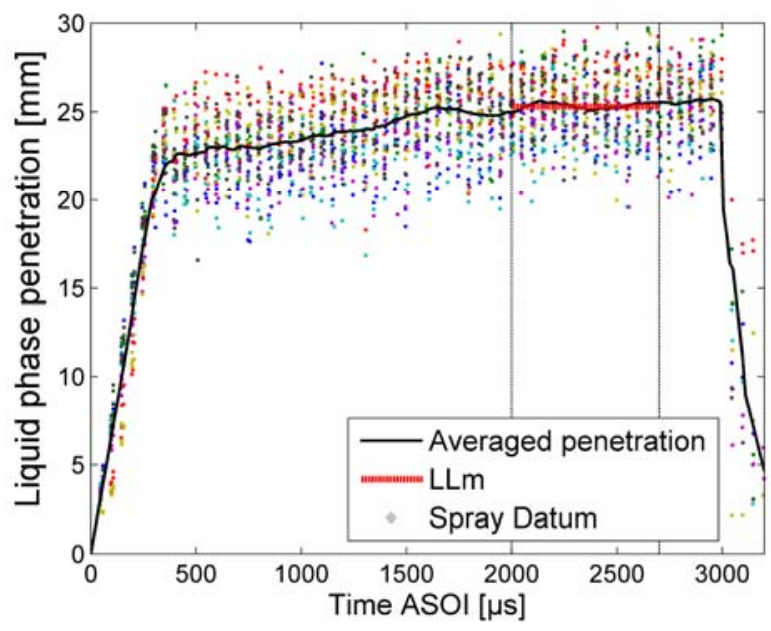

Fig 5

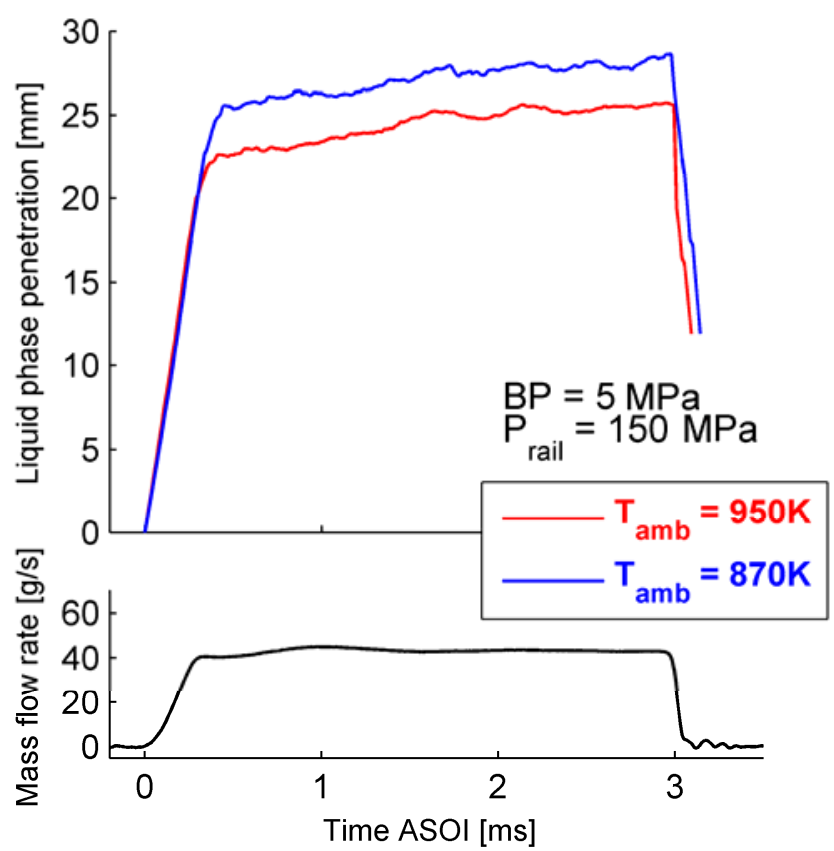

Fig 6

APPLIED ENERGY; Volume: 106; Pages: 152-162, DOI: 10.1016/j.apenergy.2013.01.027; JUN 2013 


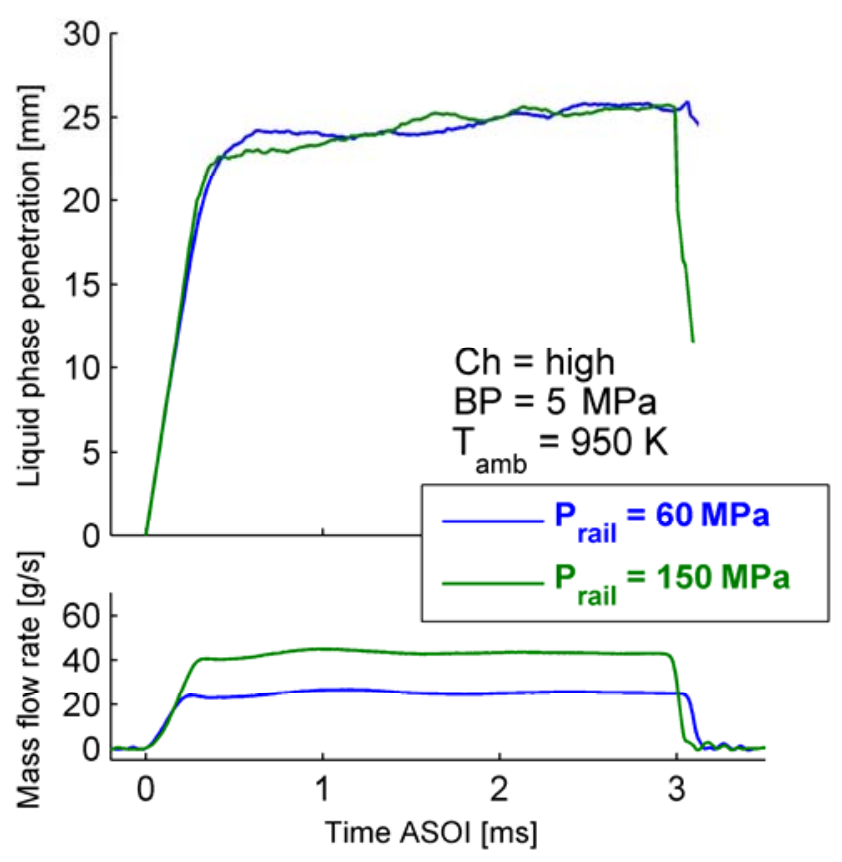

Fig 7

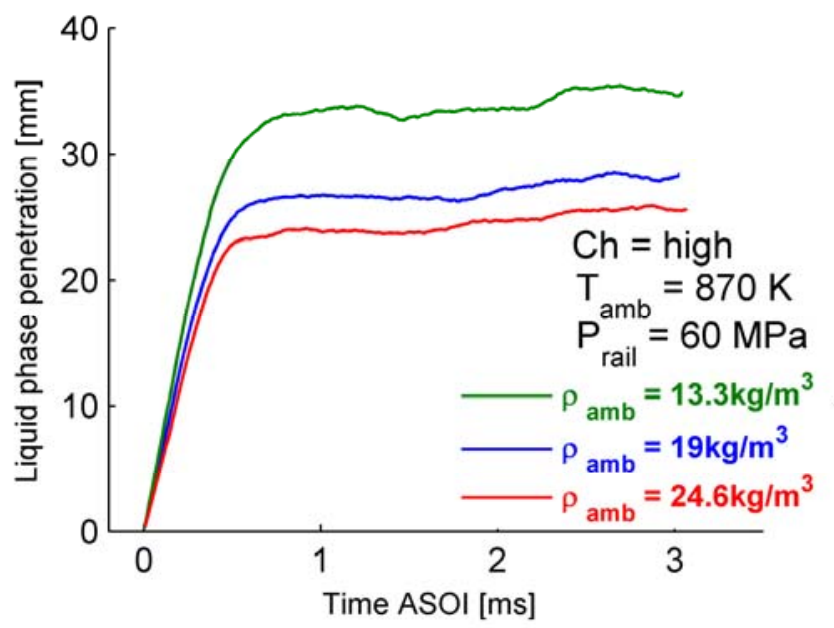

Fig 8

APPLIED ENERGY; Volume: 106; Pages: 152-162, DOI: 10.1016/j.apenergy.2013.01.027; JUN 2013 


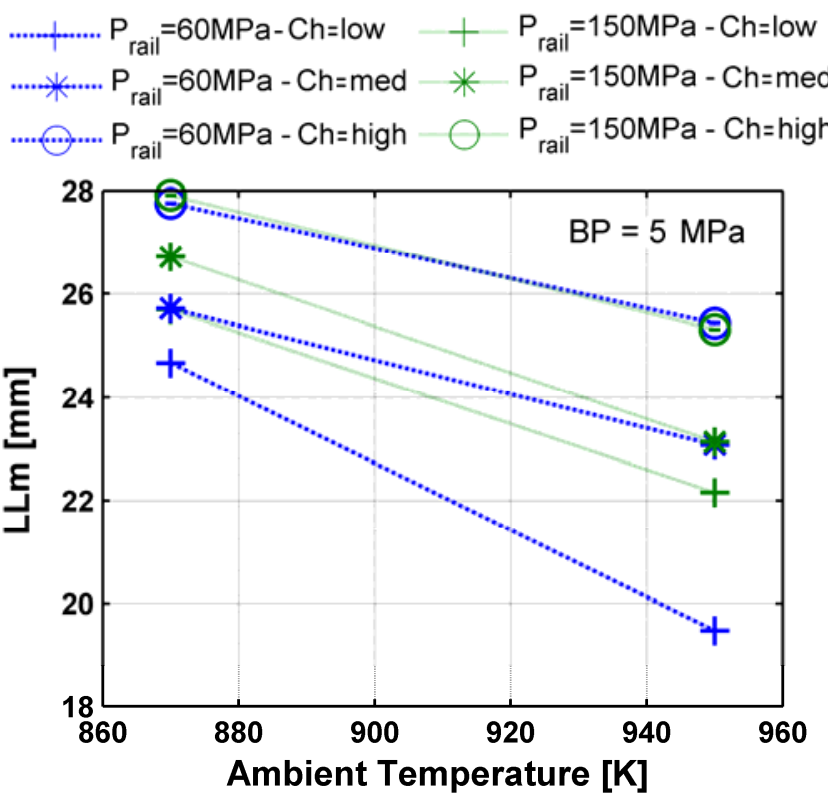

Fig 9

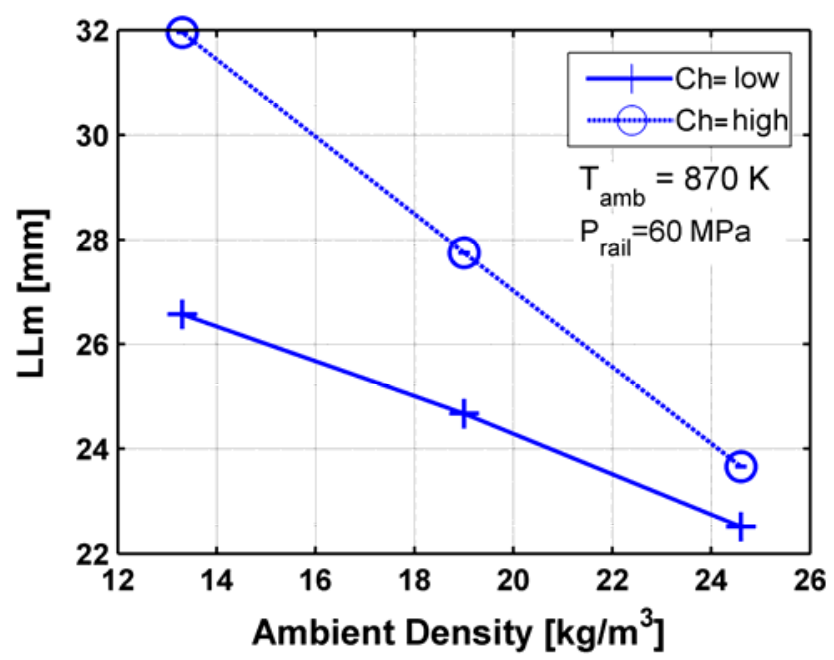

Fig 10 

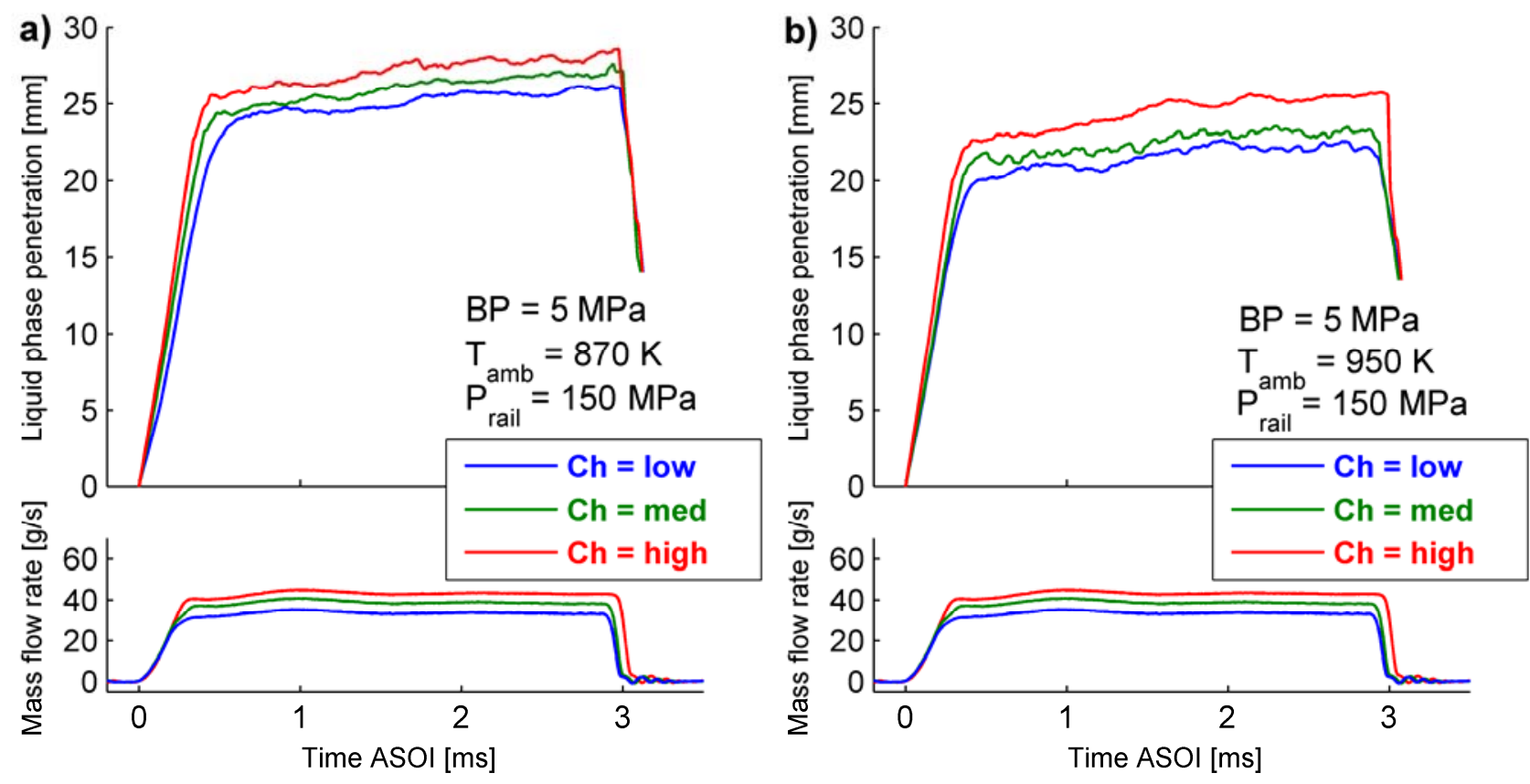

Fig 11

$\checkmark$ Prail $=60 \mathrm{MPa}-\mathrm{T}_{\mathrm{mb}}=870 \mathrm{~K}$ ...*... Prail $=150 \mathrm{MPa}-\mathrm{T}_{\mathrm{m} b \mathrm{~b}}=870 \mathrm{~K}$

a)

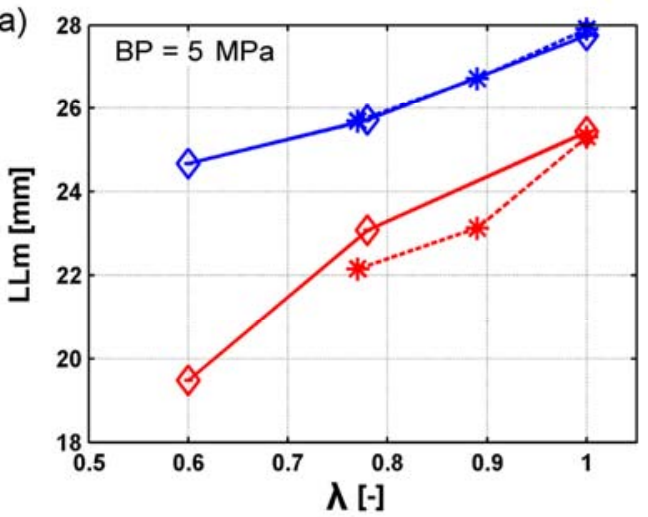

$\nabla$ Prail $=60 \mathrm{MPa}-\mathrm{T}_{\mathrm{amb}}=950 \mathrm{~K}$
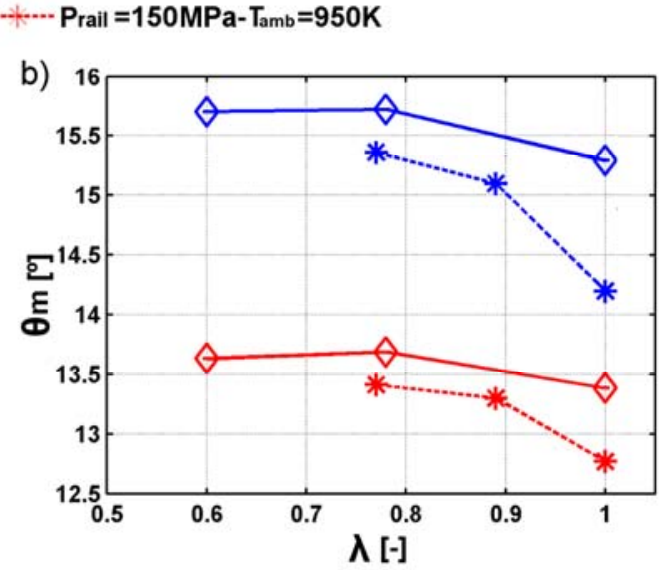

Fig 12 

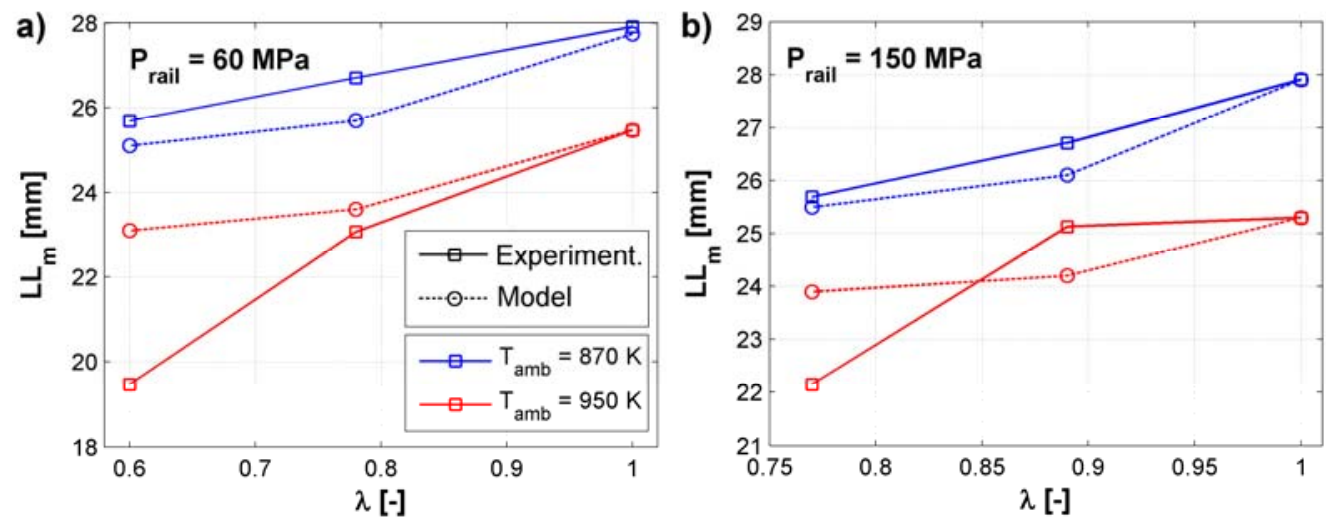

Fig 13

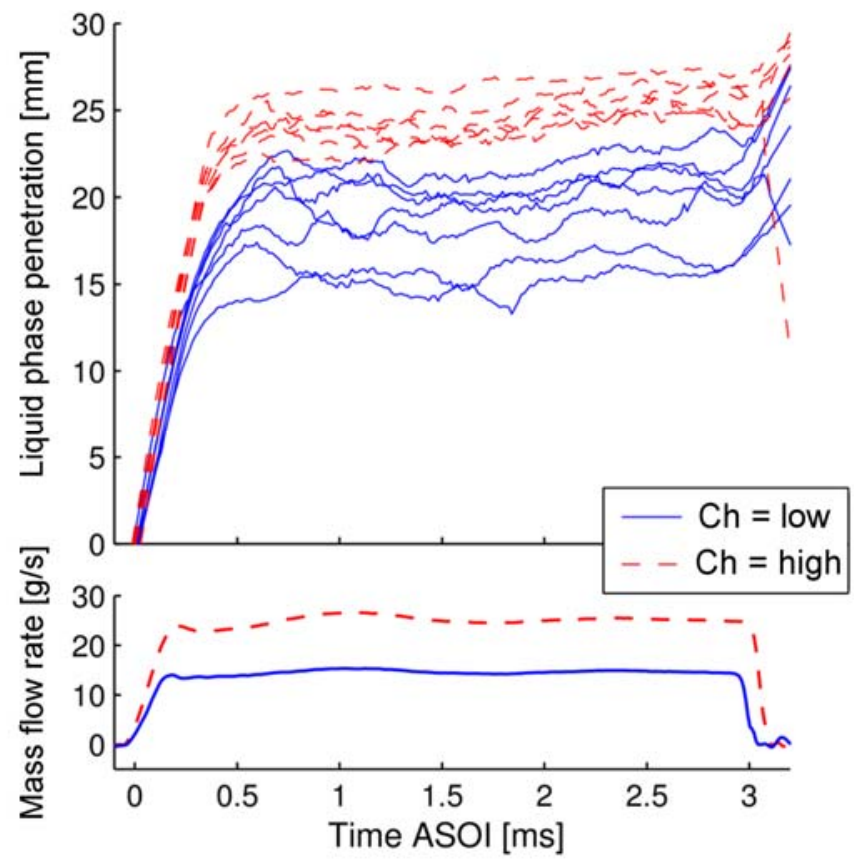

Fig 14

APPLIED ENERGY; Volume: 106; Pages: 152-162, DOI: 10.1016/j.apenergy.2013.01.027; JUN 2013 
a)

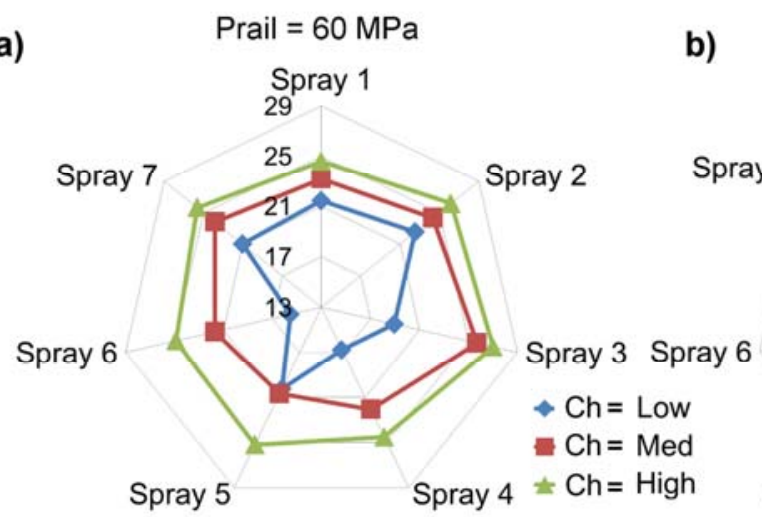

b)

$$
\text { Prail }=150 \mathrm{MPa}
$$

Spray 1

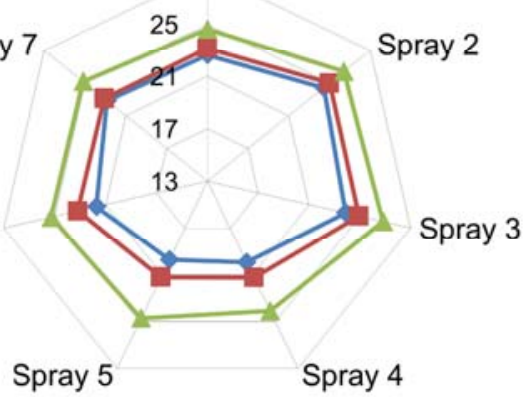

Fig 15

a)

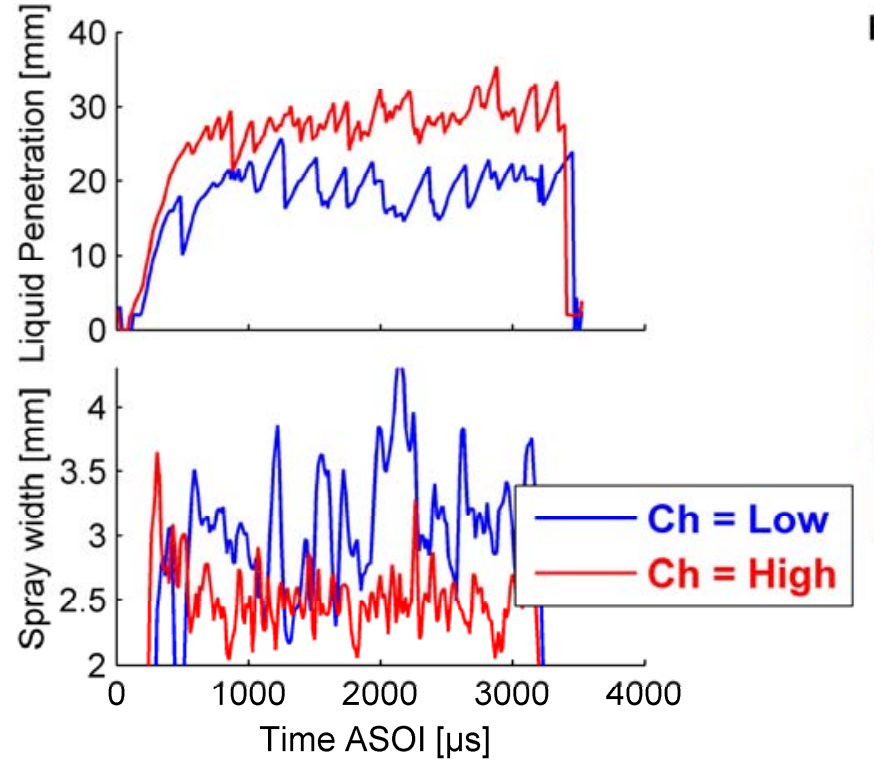

b)

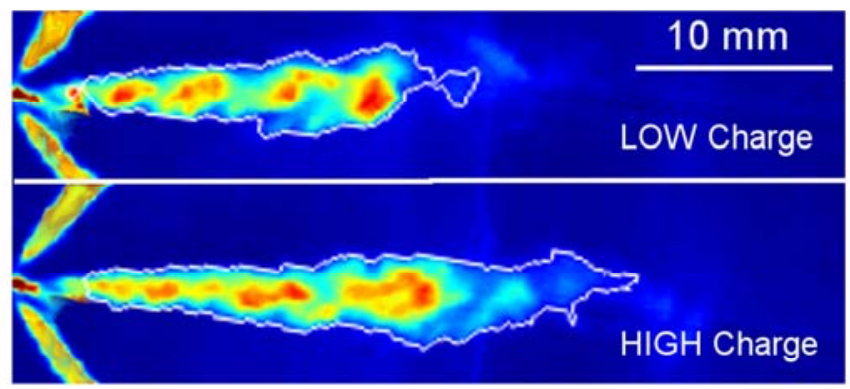

Fig 16 